\title{
Gene Mapping, Non-Human
}

National Cancer Institute

\section{Source}

National Cancer Institute. Gene Mapping, Non-Human. NCI Thesaurus. Code C18805.

Determination of the relative positions of genes from non-human organisms on a DNA molecule (chromosome or plasmid) and of the distance, in linkage units or physical units, between them. 